\title{
Effect of Power Pump and Nozzle Diameter Microbubble Generator to Increase Oxygen Concentration in Aquaculture
}

\section{Imam Taukhid1,3*, Dody Dharmawan Trijuno², Muhammad Yusri Karim², Rachman Syah ${ }^{3}$, Makmur Makmur ${ }^{3}$}

${ }^{1}$ Fisheries Science, Faculty of Marine Science and Fisheries, Hasanuddin University, Makassar, 90245, Indonesia

2 Department of Aquaculture, Faculty of Marine Science and Fisheries, Hasanuddin University, Makassar, 90245, Indonesia

${ }^{3}$ Ministry of Marine Affairs and Fisheries, Research Institute for Coastal Aquaculture and Fisheries Extension, Maros, 90512, Indonesia

Key words: Aeration, Diameter Nozzle, Microbubble Generator, Power Pump, Oxygen Contraction

\begin{abstract}
Various types of microbubble generators for use in aquaculture facilities for aeration. The aeration system is essential for high-density shrimp cultivation. However, there is a blockage in the microbubble generator aeration system, and generally, aeration at high densities requires considerable electrical power. In this study, modifications were made to various diameter nozzles and various pump power for microbubble generators. This research was conducted to determine the best microbubble by comparing the nozzle diameter and pump power. To achieve this goal, three diameter nozzles are combined with three different powers with an airflow rate of 2.5 LPM. The best combination of 32.5 $\mathrm{mm}$ nozzle diameter and 160-watt pump power. Produce bubbles ranging from $5.6-82 \mu \mathrm{m}$, with an increased oxygen concentration time of 60 minutes.
\end{abstract}

* Corresponding author. e-mail: imam_t@kkp.go.id 


\section{Introduction}

Currently, shrimp farming technology has reached high-density (Fleckenstein et al., 2020; Tierney et al., 2020; Xu et al., 2018) and super-intensive (Hostins et al., 2015; Maicá et al., 2014; Paena et al., 2018; Rahim et al., 2018; Suantika et al., 2018; Syah et al., 2017). Stocking density post larva in super-intensive shrimp culture ranges between $500-1250$ ind/m2 (Syah et al., 2017). This is in line with government policies to increase shrimp production. According to Syah et al. (2017), the orientation of the future aquaculture system with "low volume high density" is super-intensive vannamei shrimp culture technology.

An essential factor in supporting the successful aquaculture of super-intensive vannamei shrimp is the aeration system. In aquaculture, super-intensive shrimp is a combination of aeration systems: pond bottom aeration (blower) and surface aeration (paddlewheel) (Makmur et al., 2018; Rahmawati et al., 2021). Aeration process diffusion of oxygen determines the availability of dissolved oxygen (DO) in water (Boyd et al., 2018). This is done to maintain DO concentrations in aquaculture. DO is one of the most critical parameters affecting water quality (Kumar et al., 2013).

One alternative application is high-performance aerators with microbubble technology. This technology is better known as microbubble generators (MBG or MBGs) (Afisnaa et al., 2017; Alfarraj et al., 2020; Basso et al., 2018; Juwana et al., 2019; Liew et al., 2020). MBG can produce micro-sized bubbles (Deendarlianto et al., 2015; Rizaldi et al., 2019) and accelerate to increase DO concentration (Jeon et al., 2018; Rahmawati et al., 2021), and save energy (Parmar \& Majumder, 2013). There are various methods for generating a microbubble technology: Using venturi (Dey et al., 2020; Huang et al., 2021; Wang, Shuai, Zhang, et al., 2020; Wilson et al., 2021; Yadav et al., 2019), using Nozzle (Alam et al., 2018; Cheng et al., 2019; Ferrando et al., 2021; Khan et al., 2020; Kim et al., 2018; Kim \& Lee, 2021; Lee et al., 2019; Lin et al., 2018; Wu et al., 2021), using Orifice (Basso et al., 2018; Daskiran et al., 2019; Deendarlianto et al., 2015; Juwana et al., 2019; Kataoka et al., 2020; Liew et al., 2020; Miao et al., 2021; Morito \& Makuta, 2018; Rizaldi et al., 2019; Sadatomi et al., 2012), and used DAF (Kim et al., 2018; Kiuru, 2001). However, various microbubbles have a reasonably small dimension size, and some use compressors or blowers for air distribution. Thus, the application of microbubble as aeration in aquaculture often has a blockage. The use of blowers as air distribution is less effective.

Therefore, this research aims to solve the problem of MBG as an aerator in aquaculture. This innovative MBG named "DIYM $\mathrm{O}_{2}{ }^{\mathrm{Rs}}$ " has a simple design that is easy to manufacture and install. This experimental study determines the performance in increasing oxygen, which can be used as an alternative aeration system in aquaculture or other aeration systems.

\section{Materials and Methods}

The setup of the experiment is shown in Figure 1. The test section used a rectangular prism filled with water $(120 \mathrm{~cm} \times 100 \mathrm{~cm} \times 116 \mathrm{~cm})$. The airflow rate was controlled using a 2.5 LPM. The Speed gauge airflow SHLLJ Shunhuanliu Liangyi Biao, range $=0-3$ LPM. Pump using submersible Resun PG; 160, 200, and 250 Watt. Three models of Nozzle have used dimensions: 22.4, 26.45, and $32.5 \mathrm{~mm}$, while the air hole was $22.4 \mathrm{~mm}$ (Figure 1).

The dissolved oxygen meter (YSI Professional Pro Plus) was used to measure DO concentrations. Meanwhile, temperature and salinity were recorded along with DO with data transmission settings every 5 minutes. In addition, the DO meter was also connected to laptops with already installed YSI software applications for easy observation.

Chemicals used in the experiment. The performance of the MBG aeration, the DO in the test water, needs to be eliminated until its concentration reaches $0.0 \mathrm{mg} \mathrm{L}^{-1}$. Therefore, $20 \mathrm{mg} \mathrm{L}^{-1}$ of sodium sulfite $\left(\mathrm{Na}_{2} \mathrm{SO}_{3}\right)$ were used for the water deaeration through oxidation, together with $0.5 \mathrm{mg} \mathrm{L}^{-1}$ of cobalt chloride $\left(\mathrm{CoCl}_{2}\right)$ as catalyst (Adel et al., 2019). After that, the water was stirred until the DO concentration reached $0.0 \mathrm{mg} \mathrm{L}^{-1}$.

Aeration experiments. Aeration experiments were conducted in tanks of IBC 1,100 L using clean tap water. Initially, the tap water was deoxygenated using sodium sulfite and cobalt chloride, as mentioned earlier. However, it can also be performed using seawater. 
When the DO concentration reached $0.0 \mathrm{mg} \mathrm{L}^{-1}$, the MBG was operated, and simultaneous readings were taken periodically until DO increase from zero to almost $90 \%$ saturation. Furthermore, DO measurements were performed using two YSI Proplus meters, and approximately 20 readings were taken every 5 minutes. Meanwhile, the DO deficit was calculated through the slope of the best fit line, which is the natural logarithm $(Y)$ is plotted against time (X) (Jayraj et al., 2018).

The experimental apparatus features a camera that uses Nikon D7200, $60 \mathrm{~mm}$ Lens, 4 $\mathrm{mm}$ manual Flash power lighting, 2-piece Tronic Light with Full Power setting, Holly land wireless transmission type MARS 400s, using one lens aperture speed 1/160f.

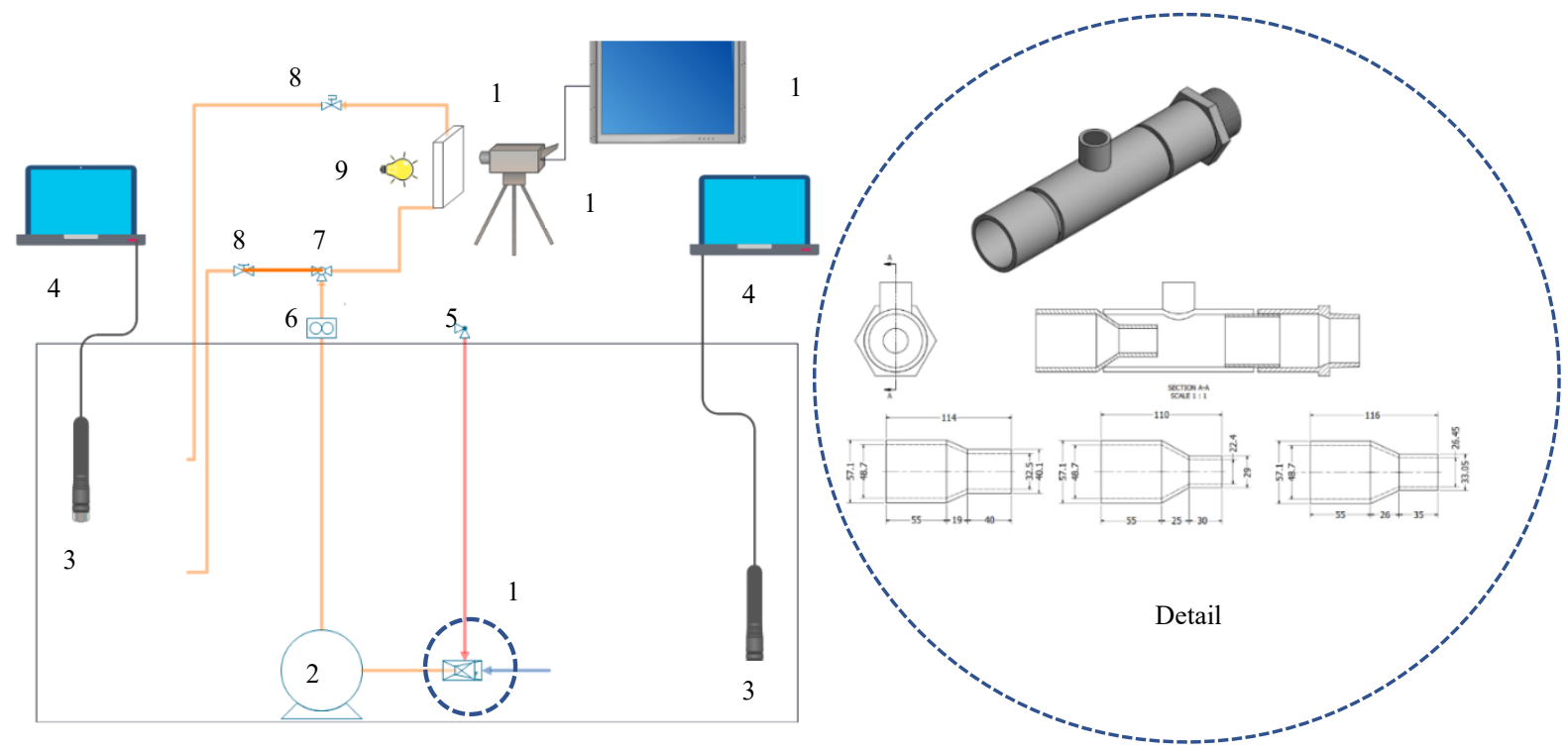

1. Nozzle, 2. Pump, 3. DO sensor, 4. Laptop, 5. Airflow rate, 6. Water Flow, 7. T elbow Y, 8. Valve, 9. Lamp, 10. Box glass, 11. Camera, 12. LED TV.

Figure 1 Experiment device different Nozzle

\section{Calculation of Analysis}

The dissolved oxygen deficit equation is as follows:

Where:

DO deficit $=\mathrm{C}_{\mathrm{s}}-\mathrm{C}_{\mathrm{m}}$

$\mathrm{Cs}$ - the dissolved oxygen concentration at saturation $\left(\mathrm{mg} \mathrm{L}^{-1}\right)$

$\mathrm{Cm}$ - the measured dissolved oxygen concentration $\left(\mathrm{mg} \mathrm{L}^{-1}\right)$.

Furthermore, the oxygen transfer coefficient equation (Boyd, 1986; Ruttanagosrigit et al., $1991)$ is described as follows:

Where:

$$
\mathrm{K}_{\mathrm{L}} \mathrm{a}_{\mathrm{T}}=\frac{\ln \left(\mathrm{DO} \text { deficit }_{10}\right)-\ln \left(\mathrm{DO} \text { deficit }_{70}\right)}{\left(\mathrm{t}_{70}-\mathrm{t}_{10}\right) / 60}
$$

Kцат - oxygen transfer coefficient $\left(\right.$ hour $\left.^{-1}\right)$.

Ln - natural logarithm.

DO deficit 10 - DO deficit at $10 \%$ saturation $\left(\mathrm{mg} \mathrm{L}^{-1}\right)$.

DO deficit7o - DO deficit at $70 \%$ saturation $\left(\mathrm{mg} \mathrm{L}^{-1}\right)$.

$\mathrm{t}_{10}$ - time at $10 \%$ saturation $(\mathrm{min})$.

t70 - time at $70 \%$ saturation ( $\mathrm{min})$.

the coefficient of oxygen transfer at a temperature of $20^{\circ} \mathrm{C}$ is calculated using the equation (ASCE, 2007; Stenstrom \& Gilbert, 1981):

$$
\mathrm{K}_{\mathrm{L}} \mathrm{a}_{20}=\mathrm{K}_{\mathrm{L}} \mathrm{a}_{\mathrm{T}} / 1.024^{\mathrm{T} 20}
$$


Where:

$\mathrm{K}_{\mathrm{L}} \mathrm{a}_{20}$ - oxygen transfer coefficient at temperature $20^{\circ} \mathrm{C}$;

1.024 - Theta factor.

The oxygen transfer rate is using the equation (ASCE, 2007; Boyd \& Tucker, 1998):

Where:

$$
\text { SOTR }=\left(\mathrm{K}_{\mathrm{L}} \mathrm{a}_{20}\right)\left(\mathrm{C}_{\mathrm{s} 20}\right)(\mathrm{V})\left(10^{-3}\right)
$$

SOTR - the standard oxygen transfer rate $\left(\mathrm{kg}^{-1}\right.$ oxygen hour $\left.{ }^{-1}\right)$.

$\mathrm{Cs}_{20}$ is the concentration ( $\mathrm{mg} \mathrm{L}^{-1}$ ) of dissolved oxygen at saturation and at $20^{\circ} \mathrm{C}$, at a measurable salinity.

$\mathrm{V}$ - the volume of the tank $\left(\mathrm{m}^{3}\right)$.

$10^{-3}$ - conversion factor ( $\mathrm{kg}$ into $\mathrm{g}$ ).

Furthermore, SOTR is defined as the amount of oxygen the aerator transfers into the water per hour. The standard aeration efficiency (SAE) is the oxygen transfer rate per unit power input (ASCE, 2007). It is calculated as follows:

$$
\mathrm{SAE}=\frac{\text { SOTR }}{\text { Power Input }}
$$

The standard oxygen transfer efficiency (SOTE) refers to the OTE at a given gas rate. The gas flow value is required to determine the OTE of the system, and the potentially suitable test devices include orifice, venturi, and pitot tubes used with appropriate traversing methods (ASCE, 2007; Eckenfelder et al., 2002; Heber et al., 2020). The equation is as follows:

Where:

SOTE $=\frac{\text { SOTR }}{W_{\text {air }}} 100$

$\begin{array}{ll}\text { Wair } & =\text { mass flow rate }(\mathrm{kg} / \mathrm{s}) \text {. } \\ \text { Wair } & =\left(1.23 \mathrm{~kg} / \mathrm{m}^{3}\right) \mathrm{Qs}, \\ \text { where Qs } & =\text { airflow speed }\left(\mathrm{m}^{3} / \mathrm{s}\right) .\end{array}$

\section{Results}

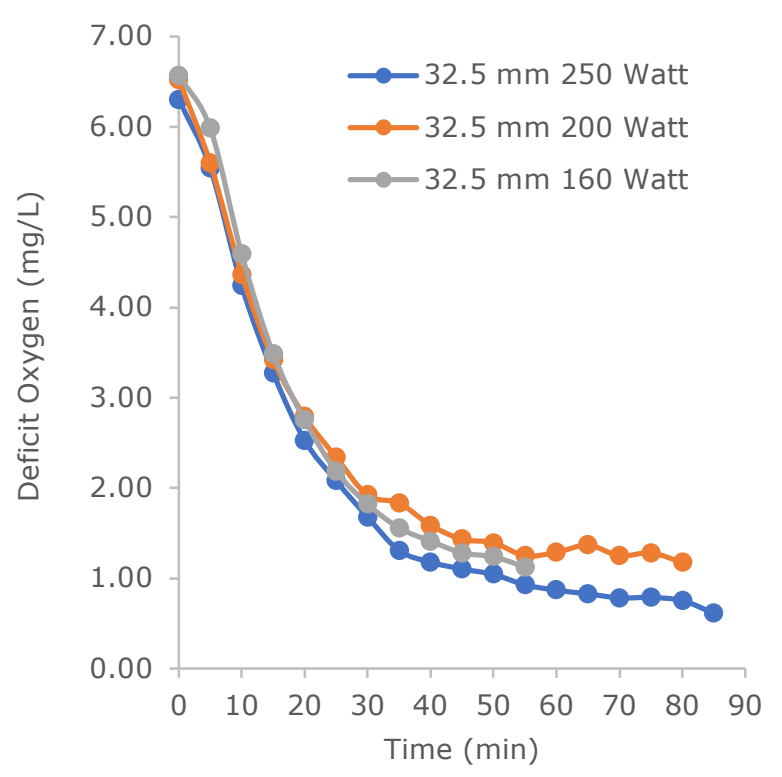

(a)

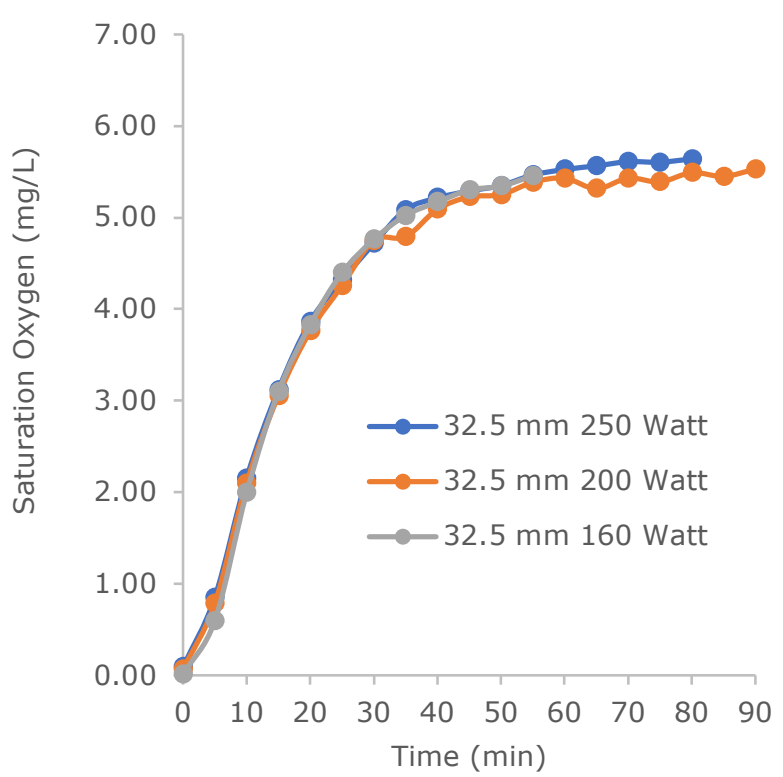

(b)

Figure 2 Comparison diameter Nozzle $32.5 \mathrm{~mm}$ and power: (a) Deficit; and (b) Saturation Oxygen 


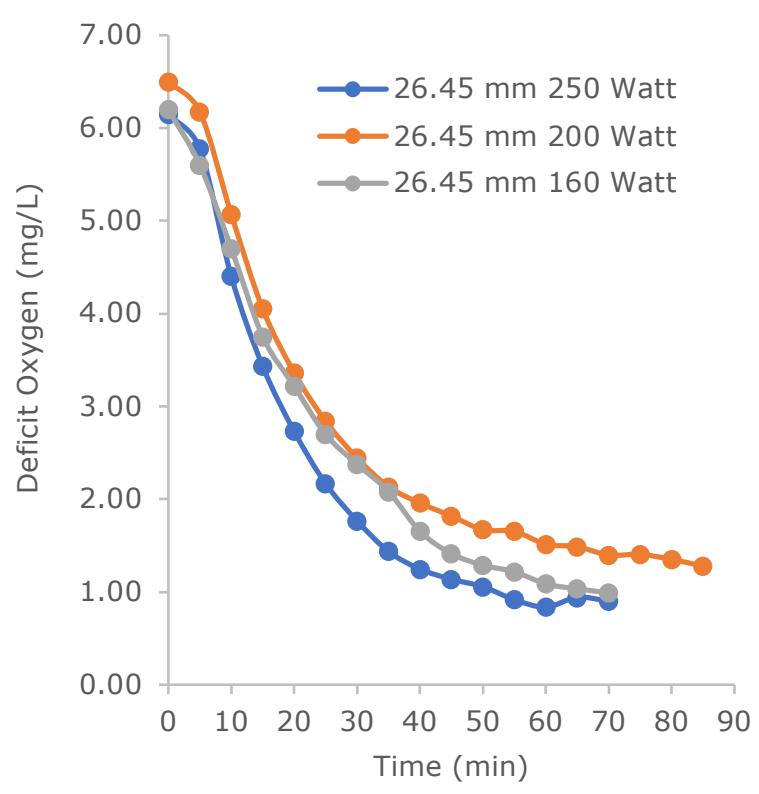

(c)

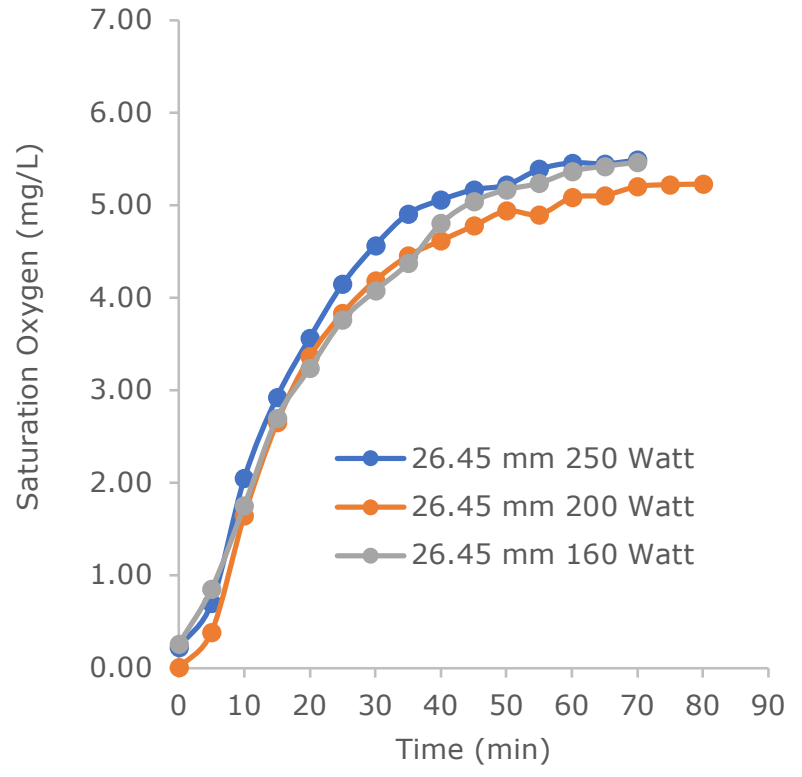

(d)

Figure 3 Comparison diameter Nozzle 26.45 and power: (c) Deficit; and (d) Saturation Oxygen

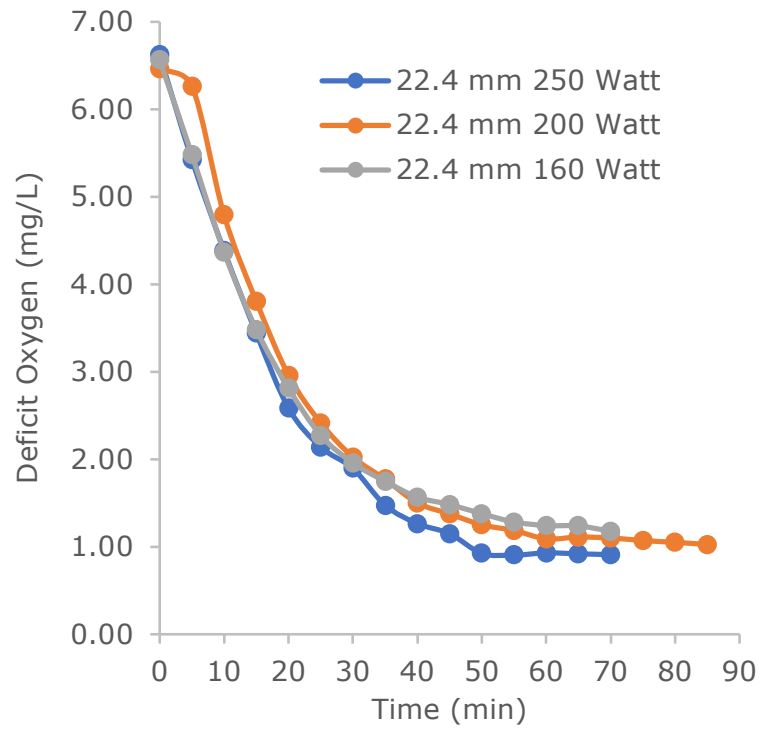

(e)

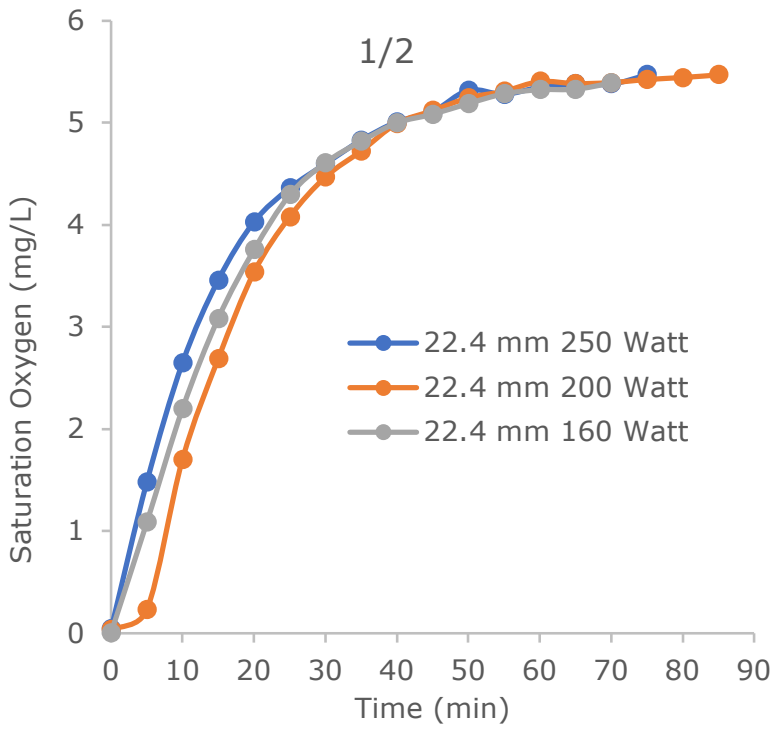

(f)

Figure 4 Comparison diameter Nozzle $22.4 \mathrm{~mm}$ and power: (e) Deficit; and (f) Saturation Oxygen

The experimental temperature between $28-29^{\circ} \mathrm{C}$ and seawater content salinity $33-34 \mathrm{ppt}$. Data interpolation is carried out when the concentration of oxygen saturation in salinity 33 and 34 is not present in the table (Boyd and Tucker 1998, p. 77). The results of the data calculation and the performance of various diameter Nozzles and power can be seen in Table 1. 
Table 1 Performance aeration Microbubble Generator

\begin{tabular}{|c|c|c|c|c|c|c|c|}
\hline $\begin{array}{l}\text { Power } \\
\text { (Watt) }\end{array}$ & $\begin{array}{c}\text { Airflow rate } \\
\text { (LPM) }\end{array}$ & $\begin{array}{c}\text { Nozzle diameter } \\
\text { (inchi) }\end{array}$ & $\begin{array}{l}\mathrm{K}_{\mathrm{LaT}} \\
(\mathrm{h})\end{array}$ & $\begin{array}{c}\mathrm{K}_{\mathrm{L}} \mathrm{a}_{20} \\
(\mathrm{~h})\end{array}$ & $\begin{array}{c}\text { SOTR } \\
\left(\mathrm{gO}_{2} / \mathrm{h}\right)\end{array}$ & $\mathrm{SAE}\left(\mathrm{gO}_{2} / \mathrm{kwh}\right)$ & SOTE \\
\hline \multirow{3}{*}{250} & & $1 / 2$ & 2.56 & 2.20 & 17.63 & 70.52 & 0.43 \\
\hline & & $3 / 4$ & 2.85 & 2.29 & 18.55 & 85.61 & 0.45 \\
\hline & & 1 & 2.91 & 2.33 & 18.95 & 75.80 & 0.46 \\
\hline \multirow{3}{*}{200} & 2.5 & $1 / 2$ & 2.64 & 2.15 & 17.44 & 87.19 & 0.42 \\
\hline & & $3 / 4$ & 1.99 & 1.67 & 13.49 & 67.47 & 0.32 \\
\hline & & 1 & 2.67 & 2.24 & 18.16 & 90.80 & 0.42 \\
\hline \multirow{3}{*}{160} & & $1 / 2$ & 2.46 & 2.07 & 16.67 & 118.33 & 0.40 \\
\hline & & $3 / 4$ & 1.87 & 1.54 & 12.46 & 77.88 & 0.30 \\
\hline & & 1 & 3.03 & 2.57 & 20.73 & 129.55 & 0.49 \\
\hline
\end{tabular}

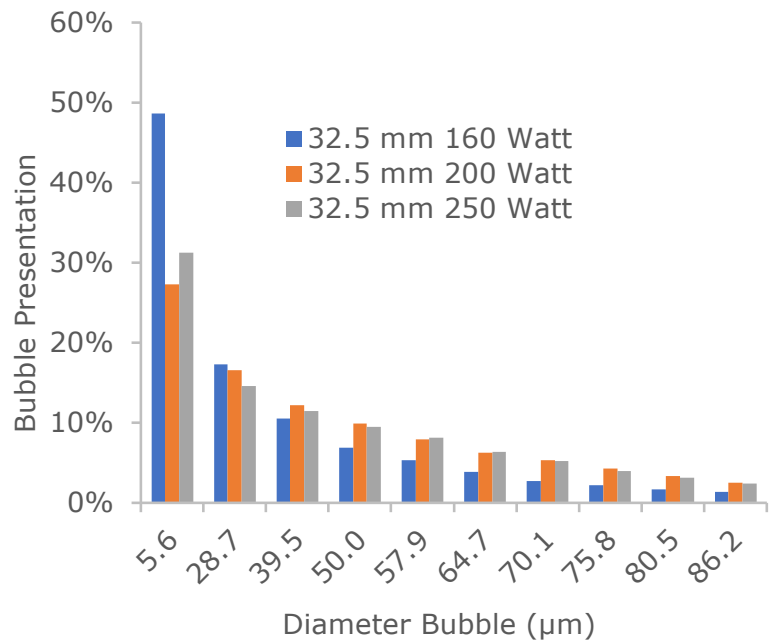

(g)

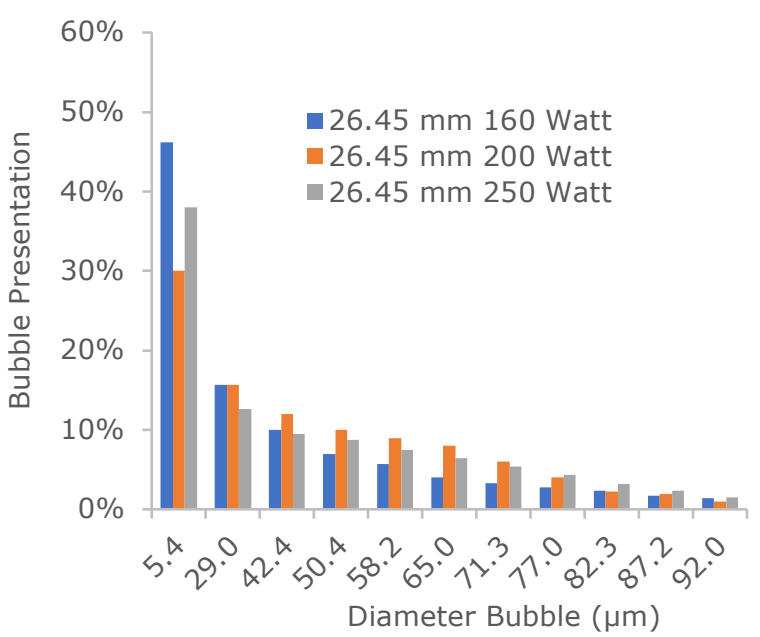

(h)

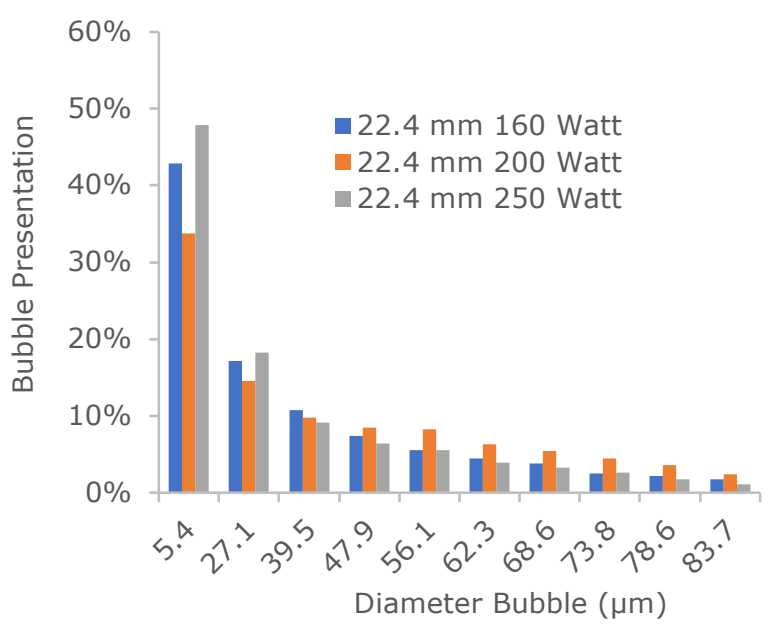

(i)

Figure 5 Comparison of production diameter bubble: (e) Diameter nozzle $32.5 \mathrm{~mm}$ (h) Diameter Nozzle $26.45 \mathrm{~mm}$ (1) Diameter nozzle $22.4 \mathrm{~mm}$.

The Israeli Journal of Aquaculture - Bamidgeh • IJA.73.2021.1547608 


\section{Discussion}

The results deficit and saturation oxygen of various diameter Nozzles and power can be seen in the Figure 2, 3, and 4. Natural logarithms of oxygen deficits known as the log deficit method (Yadav et al., 2021) were plotted versus aeration time Figure 2, 3, and 4. From there are figures, it is seen that the diameter of the Nozzle and power influence give a limited effect on the occurrence of oxygen deficit. The larger the Nozzle diameter and the lower the power, the faster the time it takes. The tank was well mixed by the aerator microbubble generator. There is a steady decrease in oxygen deficit, although not all lines touch all points $6.15-6.57$, and 55 - 90 min of aeration is drawn from the calculation results. The following parameters dissolved oxygen deficit from the water, the air-water interface area, aerator design, and the two phases' contact time (Bunea et al., 2017; Mohan et al., 2021). The fastest time to achieve oxygen saturation at a diameter of 32.5 $\mathrm{mm}$ nozzle with a power of 160 Watt is due to non-constant fluctuations in airflow rate.

When airflow is oxygenated into a microbubble generator resulting in lower deficit oxygen, this is due to a great transfer rate, but the oxygen saturation value is decreased. The results of the calculation are seen in the graph of Figure 2, 3, and $\mathbf{4}$ visible result of the oxygen concentration of downstream saturation required at the rate of transfer. The result tests were conducted at downstream saturation oxygen concentrations $0.01-0.26$ $\mathrm{mg} / \mathrm{L}$ with inlet concentrations $<0.5 \mathrm{mg} / \mathrm{L}$. When saturation oxygen levels of 5.3 or 5.47 $\mathrm{mg} / \mathrm{L}$ in the testing container, high less oxygen transfer occurs for diameter Nozzle with different power than if deficit oxygen values nearer $0.1-1.23 \mathrm{mg} / \mathrm{L}$ were acceptable. The lowest deficit oxygen was obtained by $0.75 \mathrm{mg} / \mathrm{L}$ on a 1 -inch nozzle with a power of 250 Watt.

As seen from the Figure $\mathbf{2}, \mathbf{3}$, and $\mathbf{4}$, dissolved oxygen concentration increases overtime on different nozzles and power. The diffusion rate is gradual, and the increase in dissolved oxygen concentration slows down when the oxygen concentration has reached saturation. According to Dai et al. (2020), the increased concentration of dissolved oxygen in the water can reduce the oxygen content per unit area. It is estimated that all three microbubble configurations provide proper aeration. Power pumps for aeration are also very influential. According to Daskiran et al. (2019), aeration has little effect on power generation. However, the high use of power can increase operational costs in cultivation. Aerator-related electricity costs account for about 15\% (Vinatea \& Carvalho, 2007), 45 $75 \%$ (Mohan et al., 2021), and $85-89 \%$ (Syah et al., 2017) of the total production costs in shrimp farms.

The time history plot of the dissolved oxygen concentration at different nozzle diameters and power is shown in Figure 2, 3, and 4. The green line in the Figure represented the saturated dissolved oxygen and deficit oxygen concentration when the microbubble was higher deficit oxygen and saturation oxygen concertation combination with (diameter nozzle 1-inch with pump power 160 Watt). As shown in Figure, dissolved oxygen increases rapidly up to 20 - 30 minutes after pump operation, then increases gradually until the oxygen concentration is saturated at $80-90$ minutes. The tendency of dissolved oxygen changes over time. According to Wang et al. (2020), a breakdown event causes the tiny bubbles to change into large bubbles. The size distribution of the bubble becomes homogeneous.

The variation of oxygen transfer coefficient $\mathrm{K}_{\mathrm{L}} \mathrm{aT}$ with changing diameter nozzle with power pump different value is presented in Table 1. It can be seen from Table 1 that the oxygen transfer coefficient varies with the comparison of various diameters of the Nozzle. The Кцат also varies with each power pump 250;200;160 Watt. The maximum Kцат was found to be 3.03. There is a tendency for an increase in the diameter of the Nozzle and inversely proportional to the pump's power against the mass transfer of oxygen, while the maximum KLa 20 amount obtained was 2.57 occurs in a power pump of 160 and a diameter of 1-inch Nozzle. Pambudiarto et al.(2020) are only able to produce KLat ranges between 0.03 to 0.08 . Cheng et al. (2019) produce KLa20 ranges from 0.8 to 1.8 . Zhang et al (2020) produce $\mathrm{K}_{\mathrm{L}} \mathrm{a}_{20}$ ranges from 0.8 and $\mathrm{K}_{\mathrm{L}} \mathrm{a}_{\mathrm{T}} 0.05-0.09$. 
Based on the use of microbubble, aeration of the nozzle diameter generator affects the transfer of oxygen mass. Important factors that affect the transfer of oxygen mass in a microbubble generator are the type of air, airflow rate, and installation on the inlet or pump outlet. The effect of air flow rate can accelerate the process of mass oxygen transfer (Sakamatapan et al., 2021; Taukhid et al., 2021; D. Zhang et al., 2020). The diameter of the Nozzle affects friction. The slip phenomenon results in a severe decrease in the critical flow rate and a more slip effect (Ferrando et al., 2021). It is seen that the larger the diameter of the Nozzle, shows well the performance. This is in line with the research (Han et al., 2020; Lee et al., 2019) microbubble aeration resulted in increased performance at each increase in air diameter and speed. In general system's primary oxygen mass transfer index includes $\mathrm{K}_{\mathrm{L}} \mathrm{a}_{\mathrm{T}}, \mathrm{K}_{\mathrm{L}} \mathrm{a}_{20}$ SOTR, dan SOTE (ASCE, 2007; Boyd et al., 2018; Du et al., 2020). Based on the needs of SOTR, it can easily know the combination of Nozzle diameter and power then SAE and SOTE value.

Many kinds of aerators and commercial ponds usually have a larger power unit (Abdelrahman \& Boyd, 2018). However, this study with low power can also be used as aeration. Wherein general, the installation of microbubble equipment is installed on the pump outlet. While the microbubble installer on the pump inlet results in reverse to the use of various pump power. According to Abdelrahman and Boyd (2018), the higher the pump's power, the higher the performance system aeration system. Kumar et al.(2018) high power microbubble performance are comparable to low power.

Distribution bubbles of various diameters Nozzle and power pump studied. All treatments produce bubbles of at least $4.5 \mu \mathrm{m}$ and a maximum of $92.0 \mu \mathrm{m}$. There is caused by a two-phase flow that passes through the pump impeller, and the resulting bubble is more diminutive. According to (Perissinotto et al., 2021), two-phase liquid mixtures through the impeller pump will form a cavity and produce smooth bubbles. In general, the mean bubble diameter of producing bubbles is in the microbubble category. According to ISO (2017), the category of microbubble-sized bubbles ranges from $1-100 \mu \mathrm{m}$. The most bubble percentage at bubble diameter of $5.4-5.6 \mu \mathrm{m}$ ranging from $30-49 \%$ of microbubble generators, respectively. The bubble distribution is shown in Figure 5.

Accurate bubble characterization is an essential component of any experimental investigation concerning the use and development of microbubble generators. It is of increasing importance as applications such as aeration in aquaculture and water treatment. There are still research microbubble generators that produce bubbles larger than standard. Comparative research (Huang et al., 2021) produces bubbles ranging from $0.02 \mathrm{~mm}$ to $1.28 \mathrm{~mm}$, although it uses a smaller nozzle diameter and compressor assistance as an air supply. Sakamatapan et al. (2021), using a nozzle diameter of $30 \mathrm{~mm}$, produces bubble diameters ranging from $50-130 \mu \mathrm{m}$. Ling et al., (2020), producing bubbles ranging from $50-1000 \mu \mathrm{m}$, also uses air supply with the help of compressors. While (Li et al., 2021) the bubble produces $200-1000 \mu \mathrm{m}$. Pambudiarto et al. (2020) was observed a microbubble generator in the range of $100-300 \mu \mathrm{m}$.

\section{Conclusion}

A microbubble generator is a simple component of the device, and it can increase oxygen concentration faster. Do not use compressors for air needs able to produce bubbles sized according to standards and minimize blockages-microbubble with 160 watts of pump power with a combination of $32.5 \mathrm{~mm}$ nozzle diameter. This microbubble can be used as an alternative aeration system in fishery cultivation or energy-efficient water treatment.

\section{Acknowledgments}

Thanks to La Ode Muhammad Hafiz Akbar, Zainal Abidin, Kelti Keteknikan, and Team ITP Punaga, who have helped implement this research. The authors are grateful for the financial support from the Indonesian Ministry of Marine Affairs and Fisheries, NO Grant (DIPA) BRPBAP3 (032.12.2.403828) Research Institute for Coastal Aquaculture and Fisheries Extension. 


\section{Conflicts of Interest}

The author declares no conflict of interest.

\section{Contributor statement}

Author's Contribution: Conceptualization, Imam Taukhid., Rachman Syah., Makmur; experiment, Imam Taukhid., Makmur; analysis of results, Rachman Syah., Dody Dharmawan Trijuno., Muhammad Yusri Karim; writing-preparation of the original draft, Imam Taukhid; writing-review and editing, Rachman Syah., Dody Dharmawan Trijuno., Muhammad Yusri Karim; Funding acquisition, Makmur. Respectively, as the primary contributor. All authors have read and approved the published version of the manuscript.

\section{References}

Abdelrahman, H. A., \& Boyd, C. E. (2018). Effects of mechanical aeration on evaporation rate and water temperature in aquaculture ponds. Aquaculture Research, 49(6), 21842192. https://doi.org/10.1111/are.13674

Adel, M., Shaalan, M. R., Kamal, R. M., \& Monayeri, D. S. E. (2019). A comparative study of impeller aerators configurations. Alexandria Engineering Journal, 58(4), 14311438. https://doi.org/10.1016/j.aej.2019.11.014

Afisnaa, L. P., Juwana, W. E., Indarto, Deendarlianto, \& Nugroho, F. M. (2017). Performance of Porous-Venturi Microbubble Generator for Aeration Process. Journal of Energy, Mechanical, Material and Manufacturing Engineering, 2(2), 73-80. https://doi.org/10.22219/jemmme.v2i2.5054

Alam, H. S., Redhyka, G. G., Bahrudin, Sugiarto, A. T., Salim, T. I., \& Mardhiya, I. R. (2018). Design and performance of swirl flow microbubble generator. International Journal of Engineering and Technology (UAE), 7(4), 66-69.

https://doi.org/10.14419/ijet.v7i4.40.24077

Alfarraj, B. A., Alkhedhair, A. M., Al-Harbi, A. A., Nowak, W., \& Alfaleh, S. A. (2020). Measurement of the air bubble size and velocity from micro air bubble generation (MBG) in diesel using optical methods. Energy Transitions, 4(2), 155-162.

https://doi.org/10.1007/s41825-020-00030-1

ASCE. (2007). Measurement of Oxygen Transfer in Clean Water. American Society of Civil Engineers. https://doi.org/10.1061/9780784408483

Basso, A., Hamad, F. A., \& Ganesan, P. (2018). Effects of the geometrical configuration of air-water mixer on the size and distribution of microbubbles in aeration systems. AsiaPacific Journal of Chemical Engineering, 13(6), 1-11. https://doi.org/10.1002/apj.2259

Boyd, C. E. (1986). A method for testing aerators for fish tanks. Progressive Fish-Culturist, 48, 68-70. https://doi.org/10.1577/1548-8640(1986)48<68:AMFTAF>2.0.CO;2

Boyd, C. E., Torrans, E. L., \& Tucker, C. S. (2018). Dissolved Oxygen and Aeration in Ictalurid Catfish Aquaculture. Journal of the World Aquaculture Society, 49(1), 7-70. https://doi.org/10.1111/jwas.12469

Boyd, C. E., \& Tucker, C. S. (1998). Pond Aquaculture Water Quality Management. Kluwer Academic Publishers. https://doi.org/10.1007/978-1-4615-5407-3 
Bunea, F., Nedelcu, A., \& Ciocan, D. G. (2017). Prediction of water aeration efficiency in high turbulent flow. Desalination and Water Treatment, 85, 55-62.

https://doi.org/10.5004/dwt.2017.20774

Cheng, J., Lai, X., Ye, Q., Guo, W., Xu, J., Ren, W., \& Zhou, J. (2019). A novel jetaerated tangential swirling-flow plate photobioreactor generates microbubbles that enhance mass transfer and improve microalgal growth. Bioresource Technology, 288(121531), 1-8. https://doi.org/10.1016/j.biortech.2019.03.104

Cheng, X., Xie, Y., Zhu, D., \& Xie, J. (2019). Modeling re-oxygenation performance of fine-bubble-diffusing aeration system in aquaculture ponds. Aquaculture International, 27(5), 1353-1368. https://doi.org/10.1007/s10499-019-00390-6

Dai, C., Guo, J., Liu, J., Dong, L., \& Liu, H. (2020). Experimental Study on Aeration Performance and Bubble Characteristics of Inverted Umbrella Aerator. Water, 12(10), 115. https://doi.org/10.3390/w12102809

Daskiran, C., Attiya, B., Altimemy, M., Liu, I. H., \& Oztekin, A. (2019). Oxygen dissolution via pump-turbine - Application to wastewater treatment. International Journal of Heat and Mass Transfer, 131, 1052-1063.

https://doi.org/10.1016/j.ijheatmasstransfer.2018.11.130

Deendarlianto, Wiratni, Tontowi, A. E., Indarto, \& Iriawan, A. G. W. (2015). The implementation of a developed microbubble generator on the aerobic wastewater treatment. International Journal of Technology, 6(6), 924-930.

https://doi.org/10.14716/ijtech.v6i6.1696

Dey, S., Bhattacharya, A., Kumar, P., \& Malik, A. (2020). High-rate CO2sequestration using a novel venturi integrated photobioreactor and subsequent valorization to microalgal lipids. Green Chemistry, 22(22), 7962-7973. https://doi.org/10.1039/D0GC02552F

Du, Y., Chen, F., Zhou, L., Qiu, T., \& Sun, J. (2020). Effects of different layouts of finepore aeration tubes on sewage collection and aeration in rectangular water tanks. Aquacultural Engineering, 89(102060), 1-9.

https://doi.org/10.1016/j.aquaeng.2020.102060

Eckenfelder, W. W., Malina, J. F., \& Patterson, J. W. (2002). AERATION : Principles and Practice (Vol. 11). CRC Press.

Ferrando, M., Renuke, A., Traverso, A., \& Sishtla, V. (2021). A new design method for two-phase nozzles in high efficiency heat pumps. International Journal of Refrigeration, 127, 148-156. https://doi.org/10.1016/j.ijrefrig.2021.02.023

Fleckenstein, L. J., Kring, N. A., Tierney, T. W., Fisk, J. C., Lawson, B. C., \& Ray, A. J. (2020). The effects of artificial substrate and stocking density on Pacific white shrimp (Litopenaeus vannamei) performance and water quality dynamics in high tunnel-based biofloc systems. Aquacultural Engineering, 90(102093), 1-8.

https://doi.org/10.1016/j.aquaeng.2020.102093

Han, S. W., Shin, Y .S., Kim, H. C., \& Lee, G.S. (2020). Study on the Common Rail Type Injector Nozzle Design Based on the Nozzle Flow Model. Applied Sciences, 10(2), 549. https://doi.org/10.3390/app10020549 
Heber, R. H., Reinecke, S. F., \& Hampel, U. (2020). Dynamic aeration for improved oxygen mass transfer in the wastewater treatment process. Chemical Engineering Journal, 386, 1-9. https://doi.org/10.1016/j.cej.2019.122068

Hostins, B., Braga, A., Lopes, D. L. A., Wasielesky, W., \& Poersch, L. H. (2015). Effect of temperature on nursery and compensatory growth of pink shrimp Farfantepenaeus brasiliensis reared in a super-intensive biofloc system. Aquacultural Engineering, 66, 62-67. https://doi.org/10.1016/j.aquaeng.2015.03.002

Huang, J., Sun, L., Mo, Z., Feng, Y., Bao, J., \& Tang, J. (2021). Experimental investigation on the effect of throat size on bubble transportation and breakup in small Venturi channels. International Journal of Multiphase Flow, 142(103737), 1-16. https://doi.org/10.1016/j.ijmultiphaseflow.2021.103737

Jayraj, P., Subha, M. R., Mukherjee, C. K., \& Mal, B. C. (2018). Design Characteristics of Submersible Aerator. Turkish Journal of Fisheries and Aquatic Sciences, 18(9), 10171023. https://doi.org/10.4194/1303-2712-v18_9_01

Jeon, S. Y., Yoon, J. Y., \& Jang, C.-M. (2018). Bubble Size and Bubble Concentration of a Microbubble Pump with Respect to Operating Conditions. Energies, 11(7), 1864. https://doi.org/10.3390/en11071864

Juwana, W. E., Widyatama, A., Dinaryanto, O., Budhijanto, W., Indarto, \& Deendarlianto. (2019). Hydrodynamic characteristics of the microbubble dissolution in liquid using orifice type microbubble generator. Chemical Engineering Research and Design, 141, 436-448. https://doi.org/10.1016/j.cherd.2018.11.017

Kataoka, H., Kameda, R., \& Makuta, T. (2020). Optimization of Orifice Shape and Oscillatory Displacement of an Ultrasonic Microbubble Generator to Increase Microbubble Yield. Advanced Experimental Mechanics, 5, 31-37.

Khan, P., Zhu, W., Huang, F., Gao, W., \& Khan, N. A. (2020). Micro-nanobubble technology and water-related application. Water Supply, 20(6), 2021-2035. https://doi.org/10.2166/ws.2020.121

Kim, H. S., Lim, J. Y., Park, S. Y., \& Kim, J. H. (2018). Effects of Distance of Breaker Disk on Performance of Ejector Type Microbubble Generator. KSCE Journal of Civil Engineering, 22(4), 1096-1100. https://doi.org/10.1007/s12205-017-0208-7

Kim, I., \& Lee, J. (2021). Comparison of ozonation removal for PPCPs in secondary treated sewage by microbubble generator and ejector. Environmental Engineering Research, 27(2), 200163. https://doi.org/10.4491/eer.2020.163

Kim, T., Park, H., \& Han, M. (2018). Design parameter estimations for adjustable bubble size in bubble generating system. Water Science and Technology, 77(1), 1-6.

https://doi.org/10.2166/wst.2017.470

Kiuru, H. J. (2001). Development of dissolved air flotation technology from the first generation to the newest (third) one (DAF in turbulent flow conditions). Water Science and Technology, 43(8), 1-7. https://doi.org/10.2166/wst.2001.0450

Kumar, A., Moulick, S., Singh, B. K., \& Mal, B. C. (2013). Diskontinuew: Design characteristics of pooled circular stepped cascade aeration system. Aquacultural Engineering, 56, 51-58. https://doi.org/10.1016/j.aquaeng.2013.04.004 
Kumar, M., Ranjan, S., \& Tiwari, N. K. (2018). Oxygen transfer study and modeling of plunging hollow jets. Applied Water Science, 8(5), 1-15.

https://doi.org/10.1007/s13201-018-0740-8

Lee, C. H., Choi, H., Jerng, D. W., Kim, D. E., Wongwises, S., \& Ahn, H. S. (2019). Experimental investigation of microbubble generation in the venturi nozzle. International Journal of Heat and Mass Transfer, 136, 1127-1138.

https://doi.org/10.1016/j.ijheatmasstransfer.2019.03.040

Li, X., Su, W., Liu, Y., Yan, X., Wang, L., \& Zhang, H. (2021). Comparison of bubble velocity, size, and holdup distribution between single- and double-air inlet in jet microbubble generator. Asia-Pacific Journal of Chemical Engineering, 16(2), 1-17.

https://doi.org/10.1002/apj.2611

Liew, K. C. S., Rasdi, A., Budhijanto, W., Yusoff, M. H. M., Bilad, M. R., Shamsuddin, N., Md Nordin, N. A. H., \& Putra, Z. A. (2020). Porous Venturi-Orifice Microbubble Generator for Oxygen Dissolution in Water. Processes, 8(10), 1266.

https://doi.org/10.3390/pr8101266

Lin, P. J., Chuang, M. C., \& Chang, S. C. (2018). Efficacy of using oxygen microbubble device for facultative anaerobe removal. IET Nanobiotechnology, 12(7), 973-980.

https://doi.org/10.1049/iet-nbt.2017.0232

Ling, T., Wang, T., Lei, G., Fang, Z., Zhao, L., \& Xu, C. (2020). Experimental Study on Slug Flow Characteristics and its Suppression by Microbubbles in Gas-Liquid Mixture Pipeline. Journal of Applied Fluid Mechanics, 14(2), 567-579.

https://doi.org/10.47176/jafm.14.02.31482

Maicá, P. F., de Borba, M. R., Martins, T. G., \& Wasielesky, W. (2014). Effect of salinity on performance and body composition of Pacific white shrimp juveniles reared in a super-intensive system. Revista Brasileira de Zootecnia, 43(7), 343-350.

https://doi.org/10.1590/S1516-35982014000700001

Makmur, Suwoyo, H. S., Fahrur, M., \& Rachmansyah. (2018). The influence of the number of pond bottom aeration points on white shrimp farming, Litopenaeus vannamei. Jurnal Ilmu Dan Teknologi Kelautan Tropis, 10(3), 727-738.

https://doi.org/10.29244/jitkt.v10i3.24999

Miao, J., Fan, Y., \& Wu, W. (2021). Effects of nozzle configuration on flash boiling fuel sprays of twin-orifice nozzle with aviation kerosene. International Journal of Heat and Mass Transfer, 174, 121335.

https://doi.org/10.1016/j.ijheatmasstransfer.2021.121335

Mohan, T. R., Kumar, M. S. M., \& Rao, L. (2021). Numerical modelling of oxygen mass transfer in diffused aeration systems: A CFD-PBM approach. Journal of Water Process Engineering, 40, 101920. https://doi.org/10.1016/j.jwpe.2021.101920

Morito, H., \& Makuta, T. (2018). Development and optimization of a microbubble generator with a hollow cylindrical ultrasonic horn. Journal of Chemical Engineering of Japan, 51(2), 175-179. https://doi.org/10.1252/jcej.17we082

Paena, M., Syamsuddin, R., \& Tandipayuk, H. (2018). The distribution of organic waste discharged from super-intensive vaname shrimp ( Litopenaeus vannamei ) ponds monitored using stable isotopes. AACL Bioflux, 11(4), 1089-1097. 
Pambudiarto, B. A., Mindaryani, A., Deendarlianto, \& Budhijanto, W. (2020). Evaluation of the effect of operating parameters on the performance of orifice/porous pipe type micro-bubble generator. Journal of Engineering and Technological Sciences, 52(2), 196-207. https://doi.org/10.5614/j.eng.technol.sci.2020.52.2.5

Parmar, R., \& Majumder, S. K. (2013). Microbubble generation and microbubble-aided transport process intensification-A state-of-the-art report. Chemical Engineering and Processing: Process Intensification, 64, 79-97.

https://doi.org/10.1016/j.cep.2012.12.002

Perissinotto, R. M. R. M., Monte Verde, W., Biazussi, J. L. J. L., Bulgarelli, N. A. V. N. A. V., Fonseca, W. D. P. W. D. P., Castro, M. S. de M. S. D., Franklin, E. de M. E. D. M., \& Bannwart, A. C. A. C. (2021). Flow visualization in centrifugal pumps: A review of methods and experimental studies. Journal of Petroleum Science and Engineering, 203(108582), 1-28. https://doi.org/10.1016/j.petrol.2021.108582

Rahim, R., Suantika, G., \& Muhammad, H. (2018). Performance of zero water discharge (ZWD) system with nitrifying bacteria Bacillus megaterium and microalgae Chaetoceros calcitrans components in super intensive pacific white shrimp Litopenaeus vannamei culture at low salinity. Jurnal Akuakultur Indonesia, 17(2), 137-146.

https://doi.org/10.19027/jai.17.2.137-146

Rahmawati, A. I., Saputra, R. N., Hidayatullah, A., Dwiarto, A., Junaedi, H., Cahyadi, D., Saputra, H. K. H., Prabowo, W. T., Kartamiharja, U. K. A., Shafira, H., Noviyanto, A., \& Rochman, N. T. (2021). Enhancement of Penaeus vannamei shrimp growth using nanobubble in indoor raceway pond. Aquaculture and Fisheries, 6, 277-282. https://doi.org/10.1016/j.aaf.2020.03.005

Rizaldi, M. I., Rahman, A., Deendarlianto, Prihantini, N. B., \& Nasruddin. (2019). Generation Of Microbubbles Through Single Loop And Double Loop Fluid Oscillator For Photobioreactor Aeration. International Journal of Technology, 10(7), 1446-1452.

https://doi.org/10.14716/ijtech.v10i7.3691

Ruttanagosrigit, W., Musig, Y., Boyd, C. E., \& Sukchareon, L. (1991). Effect of salinity on oxygen transfer by propeller-aspirator-pump and paddle wheel aerators used in shrimp farming. Aquacultural Engineering, 10(2), 121-131.

https://doi.org/10.1016/0144-8609(91)90005-5

Sadatomi, M., Kawahara, A., Matsuura, H., \& Shikatani, S. (2012). Micro-bubble generation rate and bubble dissolution rate into water by a simple multi-fluid mixer with orifice and porous tube. Experimental Thermal and Fluid Science, 41, 23-30.

https://doi.org/10.1016/j.expthermflusci.2012.03.002

Sakamatapan, K., Mesgarpour, M., Mahian, O., Ahn, H. S., \& Wongwises, S. (2021). Experimental investigation of the microbubble generation using a venturi-type bubble generator. Case Studies in Thermal Engineering, 27, 101238.

https://doi.org/10.1016/j.csite.2021.101238

Stenstrom, M. K., \& Gilbert, R. G. (1981). Effects of alpha, beta and theta factor upon the design, specification and operation of aeration systems. Water Research, 15(6), 643654. https://doi.org/10.1016/0043-1354(81)90156-1

Suantika, G., Situmorang, M. L., Kurniawan, J. B., Pratiwi, S. A., Aditiawati, P., Astuti, D. I., Azizah, F. F. N., Djohan, Y. A., Zuhri, U., \& Simatupang, T. M. (2018). Development of a zero water discharge (ZWD)-Recirculating aquaculture system (RAS) 
hybrid system for super intensive white shrimp (Litopenaeus vannamei) culture under low salinity conditions and its industrial trial in commercial shrimp urban farming in $G$. Aquacultural Engineering, 82, 12-24. https://doi.org/10.1016/j.aquaeng.2018.04.002

Syah, R., Makmur, M., \& Fahrur, M. (2017). Budidaya udang vaname dengan padat penebaran tinggi. Media Akuakultur, 12(1), 19.

https://doi.org/10.15578/ma.12.1.2017.19-26

Taukhid, I., Trijuno, D. D., Karim, M. Y., Syah, R., \& Makmur. (2021). Performance of a novel aeration microbubble generator in aquaculture. AACL Bioflux, 14(4), 2478-2486.

Tierney, T. W., Fleckenstein, L. J., \& Ray, A. J. (2020). The effects of density and artificial substrate on intensive shrimp Litopenaeus vannamei nursery production. Aquacultural Engineering, 89(102063), 1-5.

https://doi.org/10.1016/j.aquaeng.2020.102063

Vinatea, L., \& Carvalho, J. W. (2007). Influence of water salinity on the SOTR of paddlewheel and propeller-aspirator-pump aerators, its relation to the number of aerators per hectare and electricity costs. Aquacultural Engineering, 37(2), 73-78.

https://doi.org/10.1016/j.aquaeng.2007.02.001

Wang, X., Shuai, Y., Zhang, H., Sun, J., Yang, Y., Huang, Z., Jiang, B., Liao, Z., Wang, J., \& Yang, Y. (2020). Bubble breakup in a swirl-venturi microbubble generator. Chemical Engineering Journal, 403(126397), 1-11.

https://doi.org/10.1016/j.cej.2020.126397

Wang, X., Shuai, Y., Zhou, X., Huang, Z., Yang, Y., Sun, J., Zhang, H., Wang, J., \& Yang, Y. (2020). Performance comparison of swirl-venturi bubble generator and conventional venturi bubble generator. Chemical Engineering and Processing - Process Intensification, 154(108022), 1-12. https://doi.org/10.1016/j.cep.2020.108022

Wilson, D. A., Pun, K., Ganesan, P. B., \& Hamad, F. (2021). Geometrical Optimization of a Venturi-Type Microbubble Generator Using CFD Simulation and Experimental Measurements. Designs, 5(1), 1-18. https://doi.org/10.3390/designs5010004

Wu, Y., Liu, Z., Wang, F., Li, B., \& Gan, Y. (2021). Experimental investigation of trajectories, velocities and size distributions of bubbles in a continuous-casting mold. Powder Technology, 387, 325-335. https://doi.org/10.1016/j.powtec.2021.04.015

Xu, W. J., Morris, T. C., \& Samocha, T. M. (2018). Effects of two commercial feeds for semi-intensive and hyper-intensive culture and four $\mathrm{C} / \mathrm{N}$ ratios on water quality and performance of Litopenaeus vannamei juveniles at high density in biofloc-based, zeroexchange outdoor tanks. Aquaculture, 490(1), 194-202.

https://doi.org/10.1016/j.aquaculture.2018.02.028

Yadav, A., Kumar, A., \& Sarkar, S. (2019). Design Characteristics of Venturi Aeration System. International Journal of Innovative Technology and Exploring Engineering, 8(11), 63-70. https://doi.org/10.35940/ijitee.J9929.0981119

Yadav, A., Kumar, A., \& Sarkar, S. (2021). Performance evaluation of venturi aeration system. Aquacultural Engineering, 93(102156), 1-11.

https://doi.org/10.1016/j.aquaeng.2021.102156

Zhang, C., Song, B., Shan, J., Ni, Q., Wu, F., \& Wang, S. (2020). Design and optimization of a new tube aeration device. Aquaculture International, 28(3), 985-999.

https://doi.org/10.1007/s10499-020-00507-2 
Zhang, D., Xu, Z., Wang, G., Huda, N., \& Li, G. (2020). Environmental Technology \& Innovation Insights into characteristics of organic matter during co-biodrying of sewage sludge and kitchen waste under different aeration intensities. Environmental Technology \& Innovation, 20(101117), 1-10. https://doi.org/10.1016/j.eti.2020.101117 